\title{
Multilocational Evaluation of Growth and Antioxidant Content of Curly Kale (Brassica oleracea L. var acephala) and Chinese Kale (Brassica oleracea var. alboglabra) in Sri Lanka
}

\author{
Jayasooriya, R.Y. ${ }^{1}$, Chamara, R.M.S.R. ${ }^{1}$, Gunathilake, G.K.D.C.S. ${ }^{2}$, Liyanage, L.P.H. ${ }^{3}$ \& \\ Beneragama, C.K. ${ }^{1}$ \\ roshithajayasooriya@gmail.com,srchamara@yahoo.com, chandikaya@gmail.com, \\ harshani.pl@gmail.com,chalindab@agri.pdn.ac.lk \\ ${ }^{I}$ Department of Crop Science, Faculty of Agriculture, University of Peradeniya, Peradeniya, \\ Sri Lanka \\ ${ }^{2}$ Post Graduate Institute of Agriculture, University of Peradeniya, Peradeniya, Sri Lanka \\ ${ }^{3}$ Post Graduate Institute of Science, University of Peradeniya, Peradeniya, Sri Lanka
}

\begin{abstract}
Curly kale (Brassica oleracea var. acephala) and Chinese kale (Brassica oleracea var. alboglabra) are cruciferous vegetables, which have recently gained great popularity in the world as a 'superfood'. Generally, kale has the capacity to tolerate diverse climatic conditions while demanding fewer inputs, thus making it possible to cultivate them with a minimum cost for crop management. However, kale is still not widespread in Sri Lanka as a vegetable. Therefore, it has not been a commercialized crop to date. This study was conducted to explore the potential for cultivating kale in Sri Lanka. Two cultivars of curly kale ('Dwarf green curled' and 'Winterbor F1') and Chinese kale were cultivated in three agro-climatic zones representing three main climatic zones in the country, namely the Mid-Country Wet Zone, Mid country Intermediate Zone and Low-Country Dry Zone, using three different media $\left(\mathrm{M}_{1:}\right.$ Existing soil in each location; $\mathrm{M}_{2:}$ Sand and coir dust mixture - ratio 1:1; $\mathrm{M}_{3:}$ Sand, coir dust, and soil - ratio 1:1:1) at each location. The experiment was carried out as a three-factor factorial with three replicates as a pot experiment. Based on the present study results, even though all the varieties displayed a significantly $(\mathrm{p}<0.05)$ higher growth in terms of dry matter accumulation in the Wet Zone, the growth in the other two locations was also found to be satisfactory. Dry matter accumulation was not significantly different among the varieties within each location. Different media did not have a significant influence on growth. Even though the antioxidant contents in all varieties varied among locations, the values were within the acceptable range. Therefore, both curly kale and Chinese kale can be successfully grown in the tested locations in Sri Lanka and can be easily introduced to local consumers as a 'superfood'.
\end{abstract}

Keywords: Ascorbic acid, Chlorophyll, Climatic Zones, Dry matter, Growing media 


\section{Introduction}

Patterns of food intake play an essential role in the maintenance of the health and well-being of people. Half of the global requirement for protein and carbohydrates is provided primarily by three crops; rice, maize, and wheat (Jaenicke \& Hoschle-Zeledon, 2006), resulting in diets that contain inadequate nutrients leading to obesity and malnutrition. However, a vegetable-rich diet is considered as a good source of nutrients for a healthy life reducing many health risks. Especially, vegetables play a remarkable role in human nutrition and health since they contain dietary fiber, phytochemicals, vitamins, and minerals (Dias, 2013).

Curly kale (Brassica oleracea var. acephala) and Chinese kale (Brassica oleracea var. alboglabra) are leafy vegetables that belong to the family Brassicaceae. They are an excellent source of nutrients and other health-promoting phytochemicals such as glucosinolates, polyphenols, and carotenoids, essential for antioxidant activity (Samec et al., 2019). In addition, they are easily grown vegetables, widely accepted as a 'superfood'. Kale is an annual or biannual plant with the continuous growth of stems and leaves, which is mainly propagated by seeds. Among many types of kale in the world, curly kale and Chinese kale are predominantly popular. Leaves can be harvested four to six weeks after transplanting under optimum conditions, and they are generally consumed in a fresh form as salads and leaf juice and cooked form as soup and added to other meals as components of the decoration (Hahn et al., 2016).

Kale is one of the most demanding vegetables in some countries and can be easily grown in Sri Lanka. Nevertheless, it still lacks popularity among people in the country. It can be grown in a wide range of soils with a minimum cost for crop management. Further, it is tolerant to unfavorable climate conditions (Samec et al., 2018). However, it has not been a commercialized crop in Sri Lanka to date. Fully grown immature leaves are suitable for consumption that makes harvesting several times possible. Especially at the home garden level, few plants are good enough for family consumption. Adding this vegetable as a part of the diet at least 2-3 times a week is healthier because of its health benefits and as a change for the common vegetables that we eat daily.

Despite its enormous values, still, it is a lesspriority crop among the Sri Lankan farmers, and it is grown as a mixed crop only to very limited extents in some areas belonging to the Up-Country Wet Zone. The reason could be scarce information about the growing conditions, management practices, and health benefits. Therefore, the present experiment was conducted to investigate the possibilities of growing kale in multiple locations in Sri Lanka.

\section{Materials and Methods}

The study was carried out in three locations representing three main climatic zones in Sri Lanka, as shown in Table 1. Three different varieties: V1-Chinese kale (Brassica oleracea var. alboglabra), V2- dwarf green curled, and V3- Winterbor F1 (V2 and V3 are cultivars of curly kale), were tested in three different media (M1: Existing soil in each location; M2: Sand and coir dust mixture - ratio 1:1; M3: Sand, coir dust, and soil - ratio 1:1:1). 
The experiment was carried out as a threefactor factorial with three replicates.

A nursery was established using the standard nursery medium (sand: coir dust - 1:1 ratio). After seedlings reached the three or four leaves stage, healthy, vigorous, uniform seedlings were transplanted in poly bags $(35 \mathrm{~cm}$ diameter, black). Recommended fungicides and insecticides were applied when necessary. All plants were watered based on moisture depletion, and fertilizer application was made according to the recommendation for cabbage (DOA, 2019). Harvesting of the plants in three locations was done after six weeks of transplanting. Measurements were made from the third week after transplanting to harvesting at bi-weekly intervals. Plant dry weight was measured in shoots and roots separately (Model 18 and Gallenkamp OMT) at $72{ }^{\circ} \mathrm{C}$ for 48 hours.

\section{Table 1.}

Site characteristics of experimental locations during the experimental period

\begin{tabular}{llcccc}
\hline Experimental Location & $\begin{array}{c}\text { Agroecological } \\
\text { Zone }\end{array}$ & $\begin{array}{l}\text { Temperature } \\
\text { Range }\left(\mathrm{C}^{\circ}\right)\end{array}$ & $\begin{array}{c}\text { Annual } \\
\text { Rainfall } \\
(\mathrm{mm})\end{array}$ & $\begin{array}{c}\text { (RH) } \\
\%\end{array}$ & $\begin{array}{l}\text { Soil Type } \\
\text { of an Area }\end{array}$ \\
\hline $\begin{array}{l}\text { Dodangolla Experimental } \\
\text { station }\end{array}$ & $\begin{array}{l}\text { Intermediate } \\
\text { zone (IZ) } \\
\text { (Mid country) } \\
\text { IM3 }\end{array}$ & $20-29$ & $900-1150$ & $70-85$ & $\begin{array}{l}\text { Reddish } \\
\text { Brown } \\
\text { Latasolic }\end{array}$ \\
\hline $\begin{array}{l}\text { Mahailuppallama Sub } \\
\text { Campus* }\end{array}$ & $\begin{array}{l}\text { Dry zone (DZ) } \\
\text { (Low country) }\end{array}$ & $23-41$ & $1000-1500$ & $70-85$ & $\begin{array}{l}\text { Reddish } \\
\text { Brown } \\
\text { Earth }\end{array}$ \\
\hline $\begin{array}{l}\text { Agricultural } \\
\text { Bio-Technology Center } \\
\text { (Peradeniya)* }\end{array}$ & $\begin{array}{l}\text { Wet zone (WZ) } \\
\text { (Mid country) }\end{array}$ & $20-36$ & 2132 & $55-90 \begin{array}{l}\text { Red Yellow } \\
\text { Podzolic }\end{array}$ \\
\hline
\end{tabular}

*Under semi-open greenhouse conditions

Chlorophyll content was (1958) with minor modifications. In addition, spectrophotometrically determined according a detailed soil analysis was conducted for to Lichtenthaler (1987). Ascorbic acid content each medium at each location before and was determined with the specifictitrant 2, 6 after cultivation. The data were statistically Dichlorophenolindo- phenol according to analyzed with SAS software (SAS Institute, Hanh et al. (2016). Leaf antioxidant content, Cary, NC) and Duncan's multiple range test in the form of radical scavenging activity, was was used for pairwise comparison. measured by DDPH assay according to Blois 


\section{Results and Discussion}

Theresults of the soil analysis revealed that total Nitrogen, available Phosphorus, exchangeable Potassium, electrical conductivity (EC), soil $\mathrm{pH}$, and Cation Exchange Capacity (CEC) of the media in three locations were within the levels favorable for crop cultivation. Although the zones were identified at the agro-ecological region level as $\mathrm{WM}_{2}, \mathrm{IM}_{3}$, and $\mathrm{DL}_{1}$ (Table 1), hereafter, those regions will be referred to as WZ, IZ, and DZ for clarity. As shown in Figure 1, the Wet Zone (WZ) and Intermediate Zone (IZ) recorded significantly higher growth than that of the Dry Zone (DZ). Considering the dry weight of shoots, there was no significant $(p>0.05)$ difference between varieties in these two zones. However, plants grown in media 2 and 3 in the WZ have shown their maximum growth, whereas in the IZ, the best growth was observed in the medium 1 . A significant $(p<0.05)$ difference between varieties was noted in the DZ. Of all, variety three has recorded the highest growth in the media 2 and 3.

Each plant species has a temperature range in which it can grow at its best., and biomass accumulation in the shoot (fresh mass) is generally known to be influenced significantly by the temperature variance (Berry and Bjorkman, 1980). If the temperature increases beyond the optimum level, the crop yield losses also accelerate (Hatfield and Prueger, 2015; Lefsrud et al., 2006).

Results of the present study in the WZ and IZ are comparable to the results of previous studies. Comparatively, several degrees $\left(\mathrm{C}^{\circ}\right)$ higher temperature in the DZ may not be optimum range for maximum growth of kale.
The leaf chlorophyll content is an index of the photosynthetic potential and productivity of the plant. In addition, chlorophyll gives an indirect estimation of the plant's health status (Filella et al., 1995). In the present study, leaf chlorophyll content (Figure 2) in the WZ and DZ was reported to be higher compared to that of the IZ $(p<0.05)$. All three varieties grown in the DZ have performed well, with a higher amount of chlorophyll in all media. Further, the varieties grown in the IZ have significant differences among the three media $(p<0.05)$. Within each location, Medium 1 (M1) resulted in the highest chlorophyll content. This may be because of the high amount of N, P, K levels present in the existing soil, which directly relates to the amount of chlorophyll in leaves, as Zhang et al. (2017) explained.

Ascorbic acid (AsA) level is an important quality parameter in kale crops (Fiutak \& Michalczyk, 2020). According to Sikora and Bodziarczyk (2012), average Ascorbic acid content in kale is $62.3 \mathrm{mg} / 100 \mathrm{~g}$. Results of the present experiment revealed that AsA content in the WZ was significantly $(p<0.05)$ higher than that of the IZ and DZ (Figure 3). Within the IZ and DZ, media had a significant effect $(p<0.05)$ on the AsA content. The highest AsA content was recorded in variety 3 , irrespective of the location. According to Lee \& Kader (2000), AsA content in horticultural crops can be influenced by many factors such as pre-harvest climatic factors, genotypic differences, and cultural practices. The reduction in the AsA content in the DZ could be because of the lower light intensities experienced during the experimental period 
due to the cloud cover. Fiutak \& Michalczyk (2020) have demonstrated that a higher light intensity during the cropping period increases the content of AsA in plant tissues.

\section{Conclusions}

Both Chinese kale and curly kale can be successfully grown in the $\mathrm{WM}_{2}, \mathrm{IM}_{3}$, and $\mathrm{DL}_{1}$ regions with the existing soil in-site, without any soil amendment. The leaf yields, ascorbic acid contents, and the antioxidant activity in leaves are comparable to the values reported elsewhere. Although the yields are lower in the Low-Country Dry Zone, perhaps due to the high temperature and the low light intensities experienced during the experimental period, with possible manipulations of the environment (Fiutak \& Michalczyk, 2020), Kale can be a potential crop even in the Dry Zone (at least for DL1) of Sri Lanka. Significantly $(p<0.05)$ different among locations, the levels are well within the previously reported levels (Figure 4). The DZ resulted in the highest amount of antioxidant levels compared to those of the IZ and WZ. There was a media effect on the antioxidant content both in the $\mathrm{WZ}$ and DZ.

According to the findings, both Chinese kale and curly kale seem to be potential crops to be cultivated in all three climatic zones. However, to generalize to the whole country/ climatic zones, further experiments are needed in the other agro-ecological regions.

\section{Figure 1.}

Shoot dry matter accumulation in Chinese Kale (V1), Dwarf green curled Kale (V2) and Winterbor $F_{1}$ curly Kale (V3) grown in existing soil in-site (M1), sand: coir dust (M2) and soil: sand: coir dust (M3) at all three locations (WM, IM and $D L_{1}$ as depicted by Wet zone, Intermediate zone and Dry zone respectively). Means \pm SEM are shown (n=5). Means with the same letter on the bars within the experiment are not significantly different $(p<0.05)$. The gray horizontal box in the background represents the range of shoot dry weight reported in previous studies (author compilation).

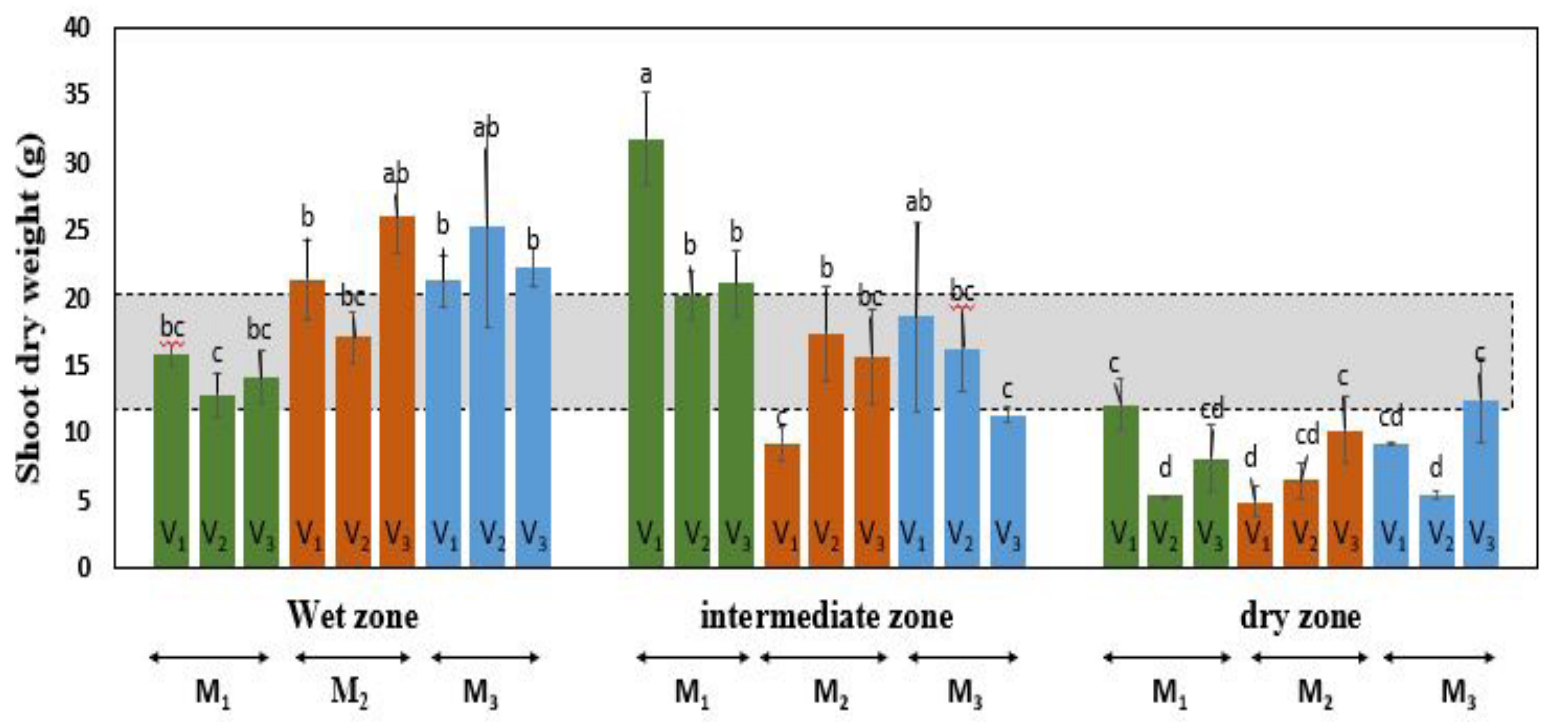


Figure 2.

Changes of leaf Chlorophyll content in Kale in three locations (see Figure 1 for details). Means with the same letter on the bars within the experiment are not significantly different $(p<0.05)$

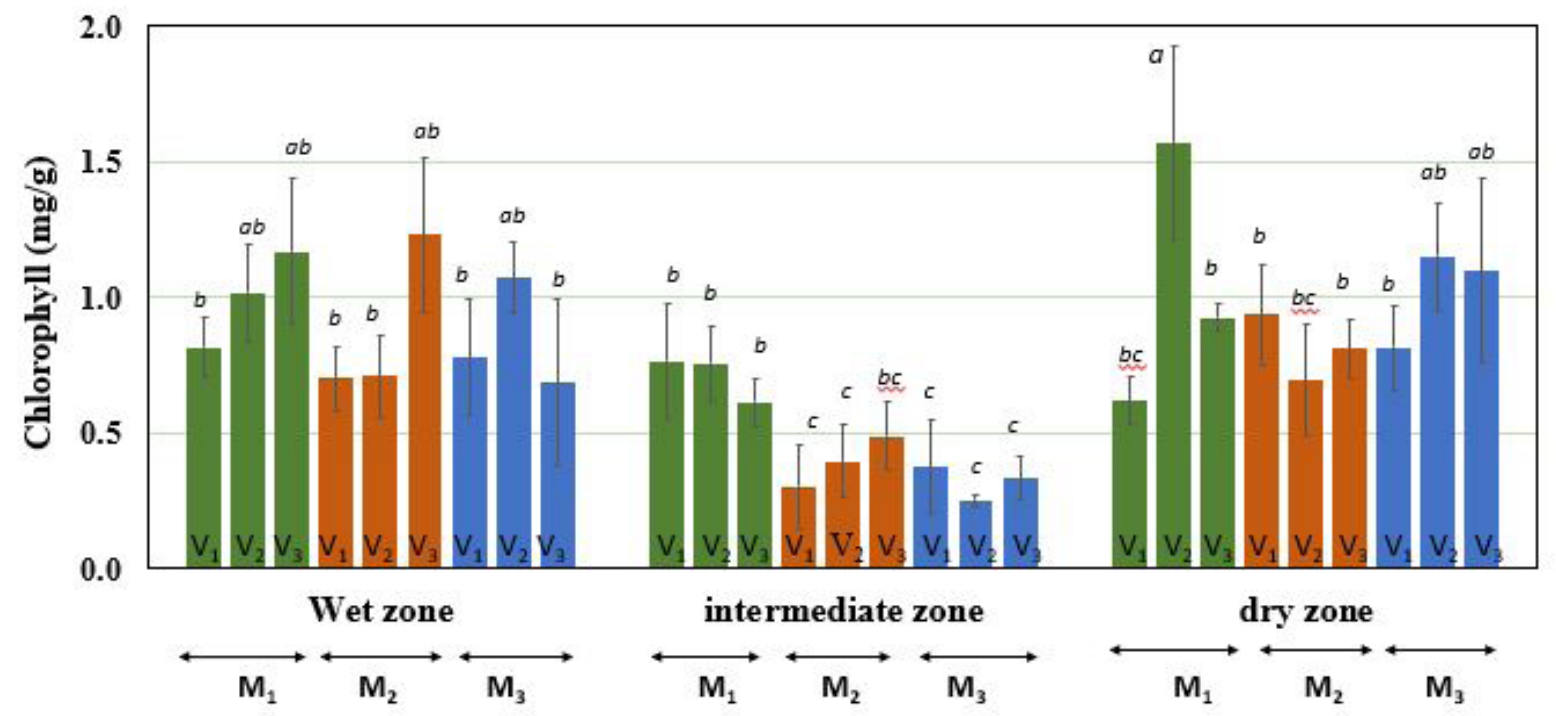

Figure 3.

Changes of Ascorbic acid content in Kale in three locations (see Figure 1 for details)

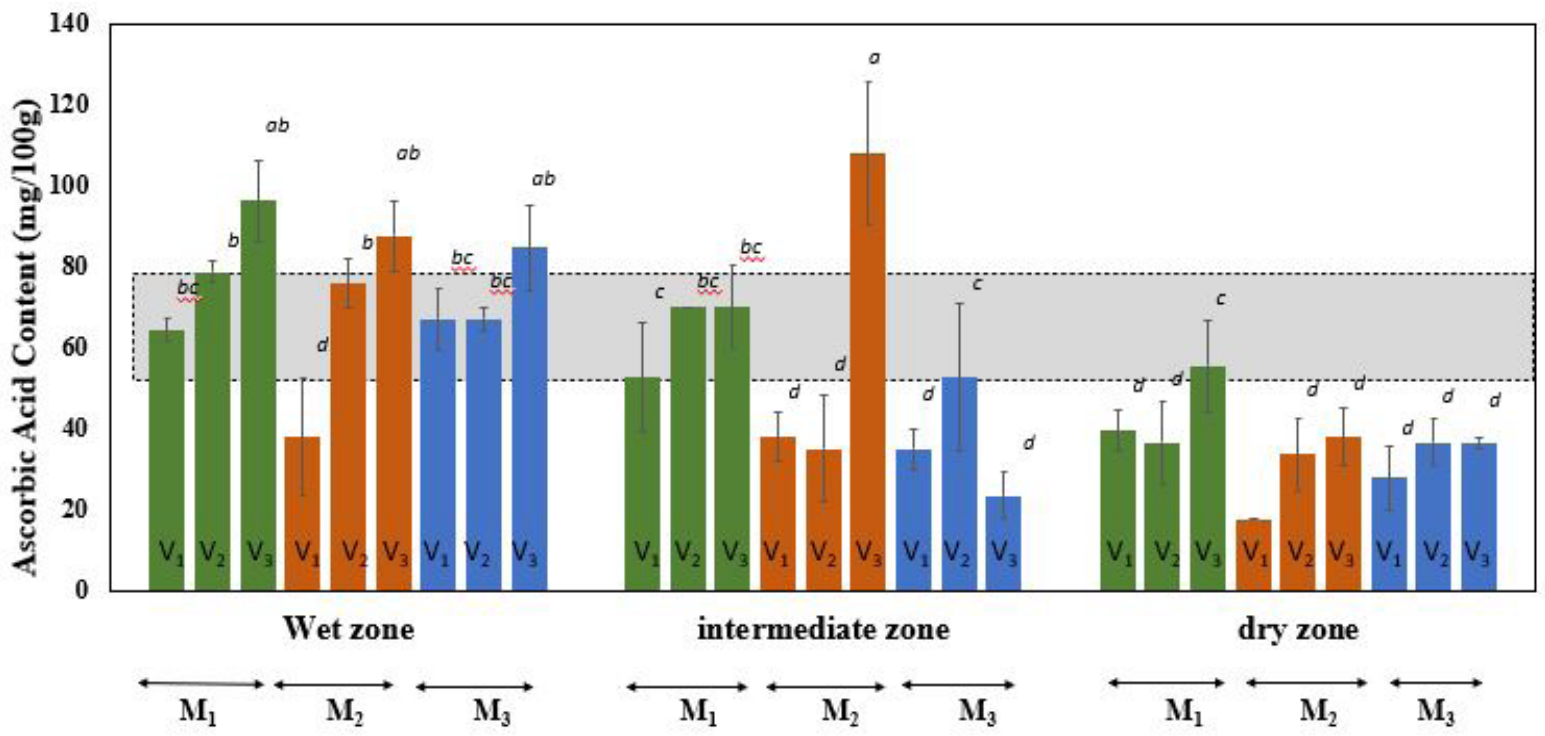


Figure 4.

Changes of Antioxidants level in Kale in three locations (see Figure 1 for details). Means with the same letter on the bars within the experiment are not significantly different $(p<0.05)$.

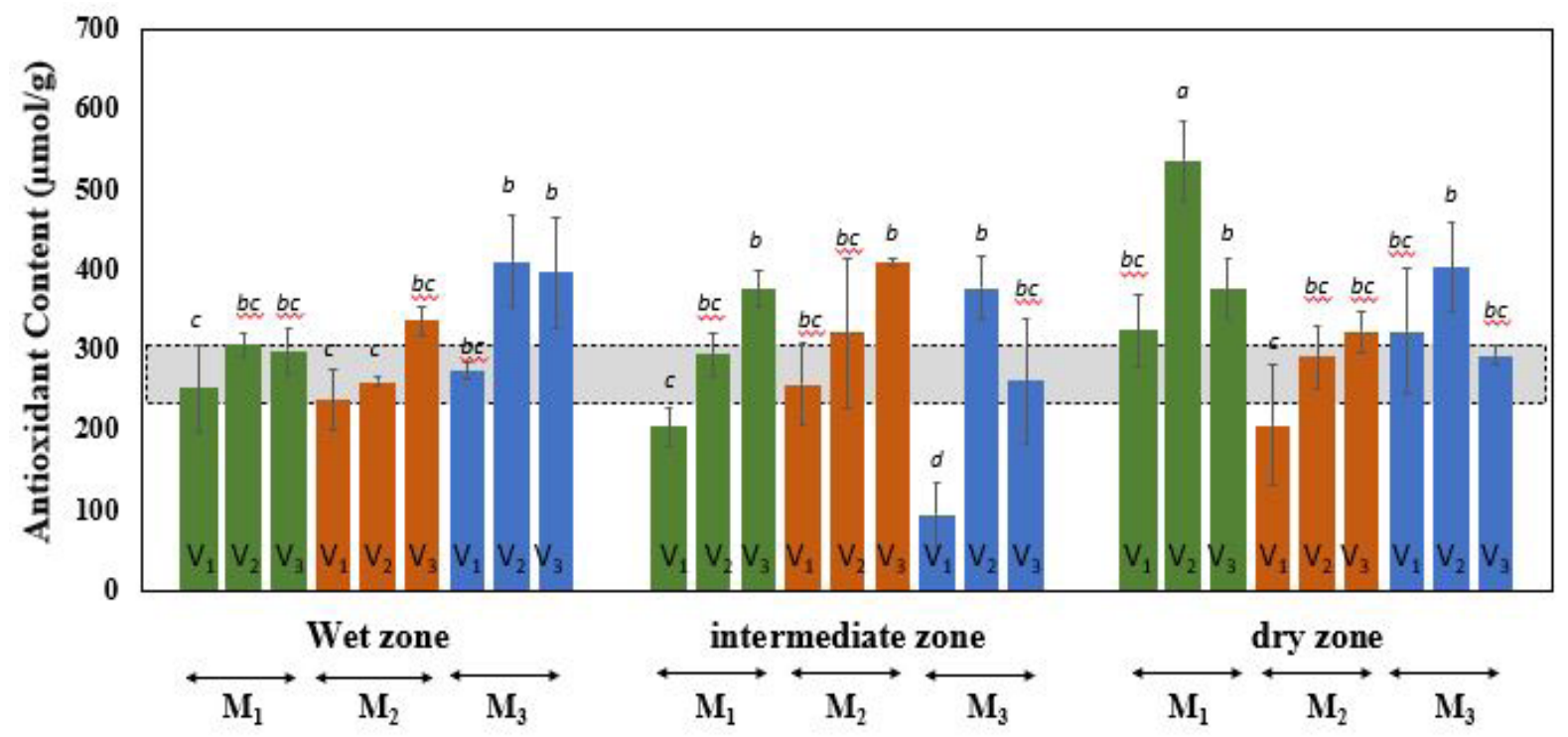

\section{Acknowledgment}

Non-academic staff members of the University Sub-Campus Mahailuppallama, Dodangolla Experimental station and Agricultural BioTechnology Center are thanked for their support for establishments and maintenance of the crop.

\section{References}

Almughraby E. Kalimullin M.I. \& Timofeeva O.A. (2018). Variability in enzymatic and non-enzymatic antioxidants Brassica oleracea var. sabellica in different growing conditions. Drug Invention Today, 10: 2981-2985.

Berry J. \& Bjorkman O. (1980). Photosynthetic response and adaptation to temperature in higher plants. Annual Review of plant physiology, 31(1): 491-543. DOI: 10.1146/annurev. pp.31.060180.002423.
Blois M.S. (1958). Antioxidant determinations by the use of a stable free radical, Nature. $\quad 181$ : 1199-1200. DOI: 10.1038/1811199a0.

Dias J. S. (2013). Vegetable breeding for nutritional quality and health benefits. In: Carbone $\mathrm{K}$, editor. Cultivar: chemical properties, antioxidant activities and health benefits. Nova Science Publishers, Inc., Hauppauge, New York: 1-81.

DOA. (2019). Cabbage cultivation guide, Horticulture Research and Development Institute, Gannoruwa, Peradeniya, Srilanka, Available at: https://www.doa.gov.lk/HORDI/index. php/en/crop-2/15-cabbage. 
Filella I., Serrano I., Serra J., \& Penuelas J. (1995). Evaluating wheat nitrogen status with canopy reflectance indices and discriminant analysis, Crop Science 35 (5):1400-1405. DOI. 10.2135/ ropsci1995.0011183X003500050023x.

Fiutak G. \& Michalczyk M. (2020). Effect of artificial light source on pigments, thiocyanates and ascorbic acid content in kale sprouts (Brassica oleracea L. var. sabellica L.). Food Chemistry: 330 (2020), 127189.DOI:10.1016/j. foodchem.2020.127189.

Hahn C. Muller A. Kuhnert N. \& Albach D. (2016). Diversity of Kale (Brassica oleracea var. sabellica): Glucosinolate content and phylogenetic relationships. Journal of agricultural and food chemistry, 64(16), 3215-3225. DOI: 10.1021/acs.jafc.6b01000.

Hanh N.T. Hoang, N.V. \& Tao P.T.P. (2016). Change of chlorophyll and vitamin $\mathrm{C}$ In green peas (Pisum Sativum) during thermal processing. Vietnam Journal of Agricultural Science, 14(7). 10681074.

Hatfield J. L. \& Prueger J. H. (2015). Temperature extremes: Effect on plant growth and development. Weather and climate extremes, 10: 4-10. DOI: 10.1016/j.wace.2015.08.001.

Jaenicke H. \& Hoschle-Zeledon I. (Eds.) (2006). Strategic framework for underutilized plant species research and development: With special reference to Asia and the Pacific, and to Sub-
Saharan Africa. International center for underutilized crops, Colombo, Sri Lanka and Global Facilitation Unit for Underutilized Species. Rome, Italy:33.

Korus A. (2011). Level of vitamin C, polyphenols, and antioxidant and enzymatic activity in three varieties of Kale (Brassica oleracea L. var. acephala) at different stages of maturity. International Journal of Food Properties, 14(5), 1069-1080: DOI: $10.1080 / 10942910903580926$.

Lee S. K. \& Kader A. A. (2000). Preharvest and postharvest factors influencing vitamin $\mathrm{C}$ content of horticultural crops. Postharvest biology and technology, 20(3), 207-220. DOI:10.1016/ S09255214(00)00133-2.

Lefsrud M. G. Kopsell D. A. Auge R. M. \& Both A. J. (2006). Biomass production and pigment accumulation in Kale grown under increasing photoperiods. HortScience, 41(3), 603-606. DOI: 10.21273/ HORTSCI.41.3.603.

Lichtenthaler H. K. (1987). Chlorophylls and carotenoids: pigments of photosynthetic biomembranes. Methods in enzymology, 148. 350-382. DOI: 10.1016/00766879(87)48036-1.

Samec D., Urlic B. \& Salopek-Sondi B. (2019). Kale (Brassica oleracea var. acephala) as a superfood: Review of the scientific evidence behind the statement. Critical reviews in food 
science and nutrition, 59(15), 24112422. DOI:10.1080/10408398.2018.14 54400 .

Sikora E. \& Bodziarczyk I. (2012). Composition and antioxidant activity of Kale (Brassica oleracea L. var. acephala) raw and cooked. Acta Scientiarum Polonorum Technologia Alimentaria, 11(3), 239-248.

Zhang J., Wang Y. ,Wang P. \& Zhang Q. Yan C. Yu F. Yi J. and Fang, L. (2017). Effect of different levels of nitrogen, phosphorus, and potassium on root activity and chlorophyll content in leaves of Brassica oleracea seedlings grown in vegetable nursery substrate. Horticulture, Environment, and Biotechnology, 58(1). 5-11. DOI: 10.1007/s13580-017-0177-2. 